\title{
Fabrication of Surface Level Cu/SiCp Nanocomposites by Friction Stir Processing Route
}

\author{
Cartigueyen Srinivasan and Mahadevan Karunanithi \\ Department of Mechanical Engineering, Pondicherry Engineering College, Pondicherry 605 014, India \\ Correspondence should be addressed to Cartigueyen Srinivasan; scartigueyen@rediffmail.com
}

Received 23 July 2015; Revised 8 November 2015; Accepted 9 November 2015

Academic Editor: Paresh Chandra Ray

Copyright ( 2015 C. Srinivasan and M. Karunanithi. This is an open access article distributed under the Creative Commons Attribution License, which permits unrestricted use, distribution, and reproduction in any medium, provided the original work is properly cited.

\begin{abstract}
Friction stir processing (FSP) technique has been successfully employed as low energy consumption route to prepare copper based surface level nanocomposites reinforced with nanosized silicon carbide particles ( $\mathrm{SiCp}$ ). The effect of FSP parameters such as tool rotational speed, processing speed, and tool tilt angle on microstructure and microhardness was investigated. Single pass FSP was performed based on Box-Behnken design at three factors in three levels. A cluster of blind holes $2 \mathrm{~mm}$ in diameter and $3 \mathrm{~mm}$ in depth was used as particulate deposition technique in order to reduce the agglomeration problem during composite fabrication. Ktype thermocouples were used to measure temperature histories during FSP. The results suggest that the heat generation during FSP plays a significant role in deciding the microstructure and microhardness of the surface composites. Microstructural observations revealed a uniform dispersion of nanosized SiCp without any agglomeration problem and well bonded with copper matrix at different process parameter combinations. X-ray diffraction study shows that no intermetallic compound was produced after processing. The microhardness of nanocomposites was remarkably enhanced and about $95 \%$ more than that of copper matrix.
\end{abstract}

\section{Introduction}

In many engineering applications, the surface properties decide the life of the components rather than their bulk properties [1]. The surface layer reinforced with ceramic particles is normally called surface composite [2]. In recent years, copper based surface composites are gaining wide spread importance in several applications due to their good mechanical, thermal, and tribological properties [3]. An extensive study on copper based surface composites is therefore needed without much loss in bulk properties of the matrix material [3]. Though several techniques are available to fabricate surface composites, friction stir processing (FSP) is a simple, green, and low energy consumption route based on the principles of friction stir welding (FSW) to fabricate surface composites with superior results [4-10]. Silicon carbide particles $(\mathrm{SiCp}$ ) are of great technological importance because of their application as reinforcement for metal matrix composites and structural ceramics with exceptional thermal shock resistance qualities [1]. Nanosized ceramic particles enhance the hardening mechanism of the composites fabricated by
FSP more effectively and therefore increase the mechanical strength compared to microsized ceramic particles [11, 12].

The heat generation during FSP is due to friction between tool and workpiece, which softens the metal matrix and the intense stirring action of the tool and aids in distribution of the reinforcement particles within the plasticized metal matrix zone. But the main difficulty in fabrication of particulate composites is the agglomeration of fine reinforcement particles [13]. The tendency of particle agglomeration can be notably reduced by appropriate designing of particulate deposition technique and tool design. Recently, Akramifard et al. [14] and Sabbaghian et al. [15] have investigated the effectiveness of designing net holes as particulate deposition technique instead of conventional groove method in copper substrate and obtained agglomeration free composites with enhanced mechanical properties using microsized $\mathrm{SiC}$ and TiC particles, respectively. Heat generation during FSP plays the key role in producing a defect free surface composite. So, the heat generation, process parameters, particulate deposition technique, and tool pin profiles are very important while fabricating surface composites by FSP route. 


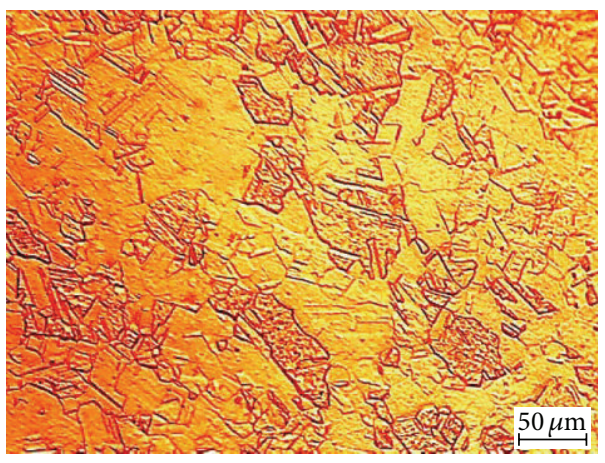

(a)

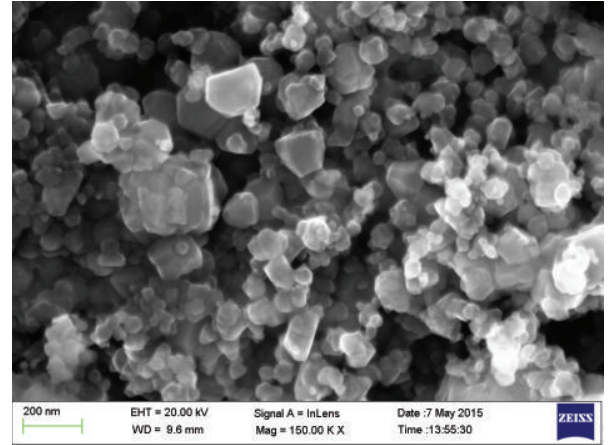

(b)
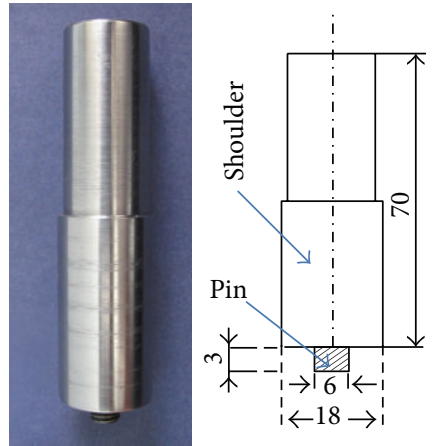

(c)

Figure 1: (a) OM of base metal, (b) FESEM of nanosized SiC particles, and (c) manufactured tool with its geometry.

The successful research on fabrication of copper based surface nanocomposites using a set of blind holes as particulate deposition technique through FSP is rarely reported till now. In this work, FSP was employed to prepare $\mathrm{Cu} / \mathrm{SiCp}$ surface nanocomposites by means of $50 \mathrm{~nm}$ SiCp using a cluster of blind holes as particulate deposition technique on the surface of $\mathrm{Cu}$ plates. The Box-Behnken design was adopted to study three factors in three levels during FSP, on the microstructure and microhardness of fabricated surface composites.

\section{Materials and Methods}

2.1. Materials. Commercially available pure (99.98\%) copper plates were procured from M/s. Mahalakshmi Metal Corporation, Chennai. Copper plates of $150 \times 50 \times 6 \mathrm{~mm}$ size were used as the base material. Nanosized $\mathrm{SiC}$ particles were purchased from M/s Sisco Research Laboratories Pvt. Ltd., India. The average particle size of as-received $\mathrm{SiC}$ particles is $50 \mathrm{~nm}$ with purity of $98 \%$. Figures 1 (a)-1(b) show the optical microscopy (OM) image of base metal and field emission scanning electron microscopy (FESEM) image of nanosized $\mathrm{SiCp}$ used in this investigation. The mean grain size of the pure copper is $35 \mu \mathrm{m}$ and the average particle size of $\mathrm{SiCp}$ is $50 \mathrm{~nm}$. A nonconsumable tool made of $\mathrm{H} 13$ tool steel and hardened to $58 \mathrm{HRC}$, having straight cylindrical threaded pin profile, was used, while the shoulder diameter was $18 \mathrm{~mm}$ and probe length and diameter were $3 \mathrm{~mm}$ and $6 \mathrm{~mm}$, respectively. The manufactured tool and its geometry are shown in Figure 1(c).

2.2. Selection of Process Parameters and Design Matrix. The following FSP parameters such as tool rotational speed, processing speed, and tool tilt angle have been selected for this study, on the basis of literature review and the influencing FSP parameters on the properties of surface composites. Table 1 shows the selected parameters and their ranges used in this study. The selected experimental design matrix based on Box-Behnken design is shown in Table 2.

2.3. Preparation of Surface Nanocomposites. Figure 2(a) depicts the experimental setup used during fabrication of surface nanocomposites by FSP route. Single pass FSP experiments were carried out in a conventional vertical milling
TABLE 1: Coded and actual values of FSP parameters.

\begin{tabular}{lcccc}
\hline Parameters & Units & \multicolumn{3}{c}{ Levels } \\
& & -1 & 0 & 1 \\
\hline Rotational speed $(\omega)$ & $\mathrm{rpm}$ & 500 & 750 & 1000 \\
Processing speed $(\nu)$ & $\mathrm{mm} / \mathrm{min}$ & 20 & 35 & 50 \\
Tool tilt angle $(\theta)$ & Degree & 0 & 1 & 2 \\
\hline
\end{tabular}

machine (3 HP and $2000 \mathrm{rpm}$ ). An axial force of $10 \mathrm{KN}$ is kept constant for all the FSP runs. In this investigation, a cluster of blind holes $2 \mathrm{~mm}$ in diameter and $3 \mathrm{~mm}$ in depth was used for $\mathrm{SiC}$ particulate deposition during composite fabrication as shown in Figure 2(b) in order to get agglomeration free surface composites $[14,15]$. Two K-type thermocouples ( $1.6 \mathrm{~mm}$ diameter/ \pm 1.1 accuracy) were used to measure the temperature distribution below the FSP tool shoulder. Thermocouples were inserted in blind holes drilled from the bottom of the copper plate near the perimeter of FSP tool shoulder and orthogonal to the path of the tool. Figure 2(c) schematically shows the actual locations of thermocouples ( $\mathrm{TCl}$ and $\mathrm{TC} 2$ ) inserted at the advancing side (AS) and the retreating side (RS) prior to FSP runs. A four-channel temperature data logger was used to record the temperature readings.

2.4. Characterization of Surface Nanocomposites. Microstructural observations were carried out by optical microscopy (OM), scanning electron microscopy (SEM), and field emission scanning electron microscopy (FESEM) as per ASTM standards. X-ray diffractometer (XRD) was used to examine the phase composition for both nanosized SiC particles and the fabricated nanocomposites. Vickers microhardness in the stir zone was measured across the cross section of the sample from 5 points ( $\pm 1 \%$ accuracy) and the average of the results was reported. The Vickers microhardness points were chosen $1.5 \mathrm{~mm}$ below the FSP surface and checked with a constant load of $0.25 \mathrm{Kgf}$ with a dwelling period of 15 seconds.

\section{Results and Discussion}

3.1. Surface and Macroscopic Analysis. In all FSP runs, the tool shoulder was plunged to $0.1 \mathrm{~mm}$ depth beneath 
TABLE 2: Box-Behnken design matrix with peak temperature, grain size of $\mathrm{Cu}$, and microhardness.

\begin{tabular}{|c|c|c|c|c|c|c|c|}
\hline \multirow{2}{*}{ Run } & \multirow{2}{*}{ Std. order } & \multicolumn{3}{|c|}{ FSP parameters } & \multirow{2}{*}{$\begin{array}{c}\text { Peak temperature } \\
\left({ }^{\circ} \mathrm{C}\right)\end{array}$} & \multirow{2}{*}{$\begin{array}{l}\text { Grain size of matrix after FSP } \\
\qquad(\sim \mu \mathrm{m})\end{array}$} & \multirow{2}{*}{$\begin{array}{c}\text { Average hardness } \\
(\mathrm{Hv})\end{array}$} \\
\hline & & $\omega(\mathrm{rpm})$ & $v(\mathrm{~mm} / \mathrm{min})$ & $\theta$ (degree) & & & \\
\hline 1 & 14 & 750 & 35 & 1 & 416 & 4 & 167.6 \\
\hline 2 & 15 & 750 & 35 & 1 & 412 & 4 & 166.5 \\
\hline 3 & 3 & 500 & 50 & 1 & 352 & 1.5 & 189.3 \\
\hline 4 & 9 & 750 & 20 & 0 & 462 & 5 & 149.8 \\
\hline 5 & 16 & 750 & 35 & 1 & 414 & 4 & 166.9 \\
\hline 6 & 13 & 750 & 35 & 1 & 415 & 4 & 167.9 \\
\hline 7 & 1 & 500 & 20 & 1 & 422 & 3 & 164.6 \\
\hline 8 & 10 & 750 & 50 & 0 & 381 & 3.5 & 168.3 \\
\hline 9 & 7 & 500 & 35 & 2 & 358 & 2 & 173 \\
\hline 10 & 11 & 750 & 20 & 2 & 451 & 5 & 151.2 \\
\hline 11 & 2 & 1000 & 20 & 1 & 513 & 7 & 148.7 \\
\hline 12 & 6 & 1000 & 35 & 0 & 438 & 6 & 153.7 \\
\hline 13 & 8 & 1000 & 35 & 2 & 430 & 6 & 156.4 \\
\hline 14 & 4 & 1000 & 50 & 1 & 384 & 5 & 168.1 \\
\hline 15 & 5 & 500 & 35 & 0 & 362 & 2 & 171.2 \\
\hline 16 & 17 & 750 & 35 & 1 & 418 & 4 & 167.4 \\
\hline 17 & 12 & 750 & 50 & 2 & 372 & 3.5 & 169.5 \\
\hline
\end{tabular}

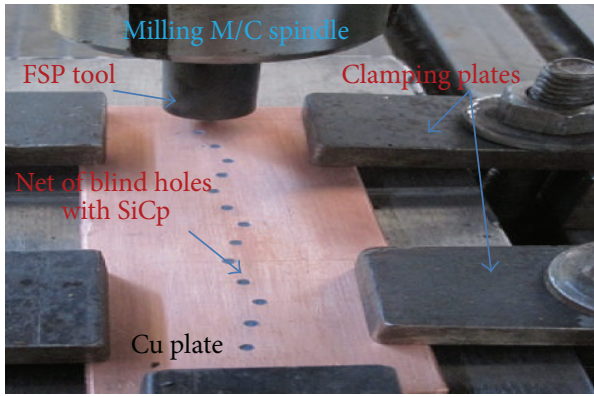

(a)

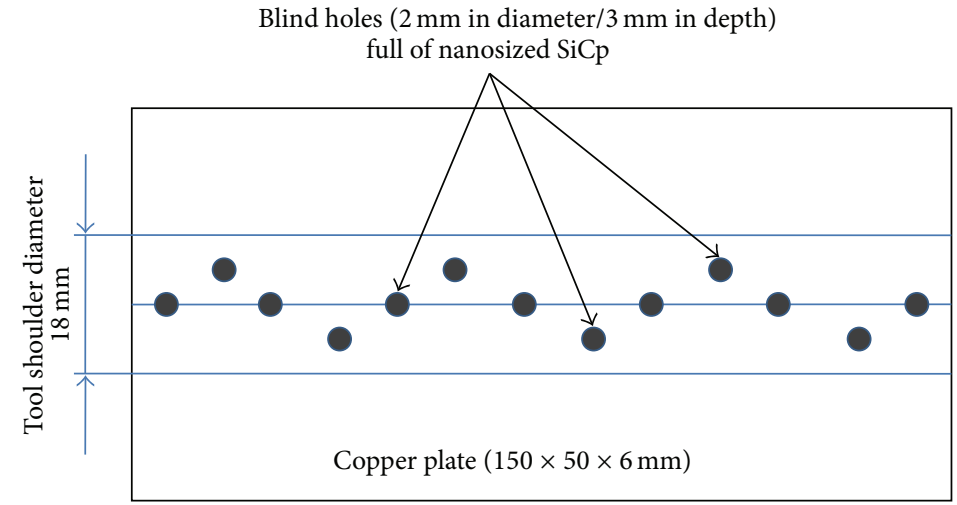

(b)

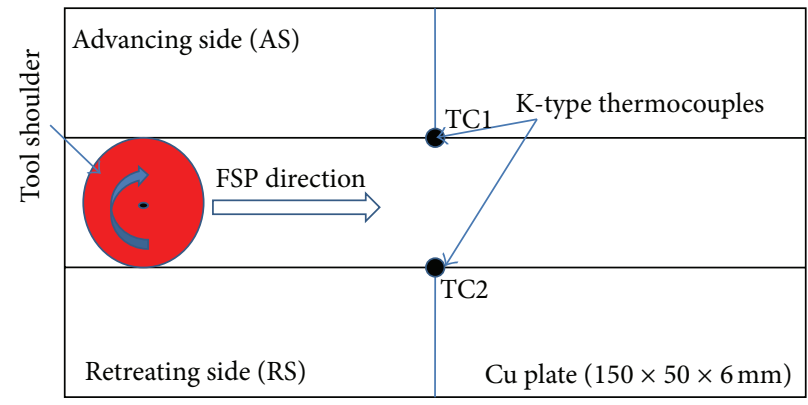

(c)

FIGURE 2: (a) Experimental setup, (b) design of blind holes on Cu plate, and (c) thermocouple locations.

the plate surface to achieve effective contact for frictional heating to obtain a good formation in the processed zone. Figure 3(a) shows the fabricated surface nanocomposites as per the design matrix (Table 2). It is essential to obtain a smooth crown appearance owing to the fact that each surface irregularity in the crown leads to another kind of internal defects in the surface composite [16]. The typical crown appearances were observed in almost all samples without any surface defects. Another point in this research is shape of stir zone (SZ). It was observed that different shapes of stir zones were obtained at different process parameter combinations during FSP as shown in Figure 3(b). 


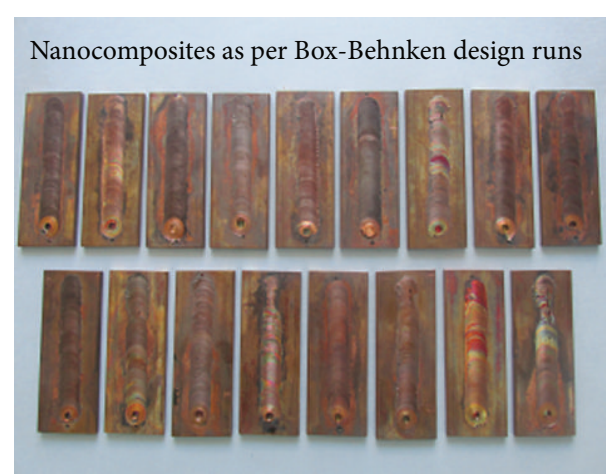

(a)

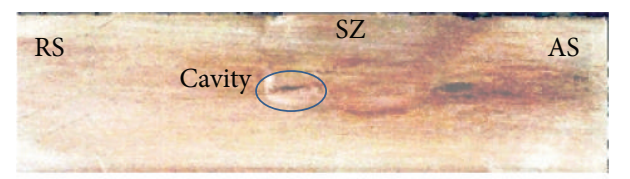

(i) $500 \mathrm{rpm} / 35 \mathrm{~mm} / \mathrm{min} / 0^{\circ}$

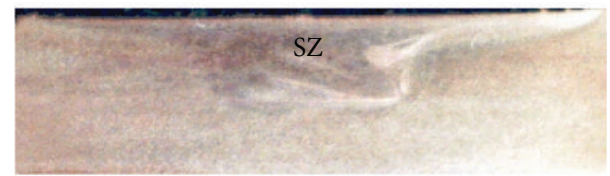

(ii) $500 \mathrm{rpm} / 20 \mathrm{~mm} / \mathrm{min} / 1^{\circ}$

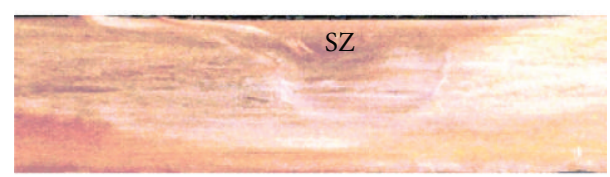

(iii) $750 \mathrm{rpm} / 20 \mathrm{~mm} / \mathrm{min} / 2^{\circ}$

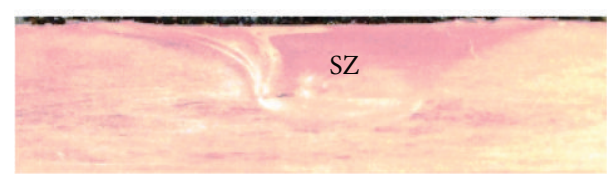

(iv) $1000 \mathrm{rpm} / 35 \mathrm{~mm} / \mathrm{min} / 2^{\circ}$

(b)

Figure 3: (a) Fabricated Cu/SiCp surface nanocomposites and (b) macrostructure of fabricated nanocomposites at different process parameter combinations.

The results indicated that lower rotational speed (500 rpm) resulted in generation of basin shaped stir zone with cavity defects in the retreating side of SZ due to low heat-input as well as poor compaction/forging action during FSP because of zero tool tilt angle in Figure 3(b)(i), whereas inverted trapezoidal shaped SZs were obtained at different rotational speeds (500, 750, and $1000 \mathrm{rpm})$ without any defects in Figure 3(b)(ii-iv) with higher tool tilt angles. These indicate that, with the same tool geometry, different SZ shapes can be produced at different heat-inputs by changing FSP process parameters.

\subsection{Heat Generation and Measurement of Peak Tempera-} ture. Researchers have developed different heat generations models for FSW/P techniques. The expression for total heat generation $(Q)$ during FSW/FSP in generalized form (1) is given below, where the value of " $X$ " depends on tool pin profile and, for straight cylindrical pin profile, is 3 [17]:

$$
Q=\frac{2}{3} \pi \omega \mu \tau\left[R^{3}+X \cdot r^{2} \cdot h\right] \text {. }
$$

From (1), the heat-input $(Q)$ has direct relation with rotational speed and reverse relation with processing speed as shown by

$$
Q \propto \frac{\omega}{v} .
$$

According to (2), the heat-input increases as " $\omega$ " is increased or " $v$ " is decreased, and, therefore, higher peak temperature at higher rotational speed/lower processing speed has resulted. Figure 4(a) shows the typical temperature distribution profile of sample in both advancing side (AS) and retreating side (RS) during FSP at $750 \mathrm{rpm}, 20 \mathrm{~mm} / \mathrm{min}$, and $2^{\circ}$ using $\mathrm{K}$ type thermocouples. This curve gives important information, not only about the maximum temperature reached by the processed material, but also about heating and cooling rates of the material during FSP. Figure 4(b) depicts the peak temperature histories in the AS and RS during all FSP runs. It was observed that the temperatures on the AS were slightly higher than those on the RS in all process parameter combinations. These results are consistent with Cartigueyen et al. [18] and Hwang et al. [19] on pure copper.

Though the rotational $(\omega)$ and processing $(\nu)$ speeds are two main effective parameters for heat generation during FSP, however, the increase of tool tilt angle from $0^{\circ}$ to $2^{\circ}$ provides good forging/compaction (reducing porosity), effective stirring action, frictional forces, and material flow pattern in SZ during FSP which leads to a reasonable change in heat generation. The following significant information can be derived from Figures 4(a)-4(b) and from Table 2: (i) the peak temperature at the advancing side reached during fabrication of surface nanocomposites by FSP varying between $352^{\circ} \mathrm{C}$ and $513^{\circ} \mathrm{C}$ which is $0.33-0.48$ of the melting point of pure copper $\left(\sim 1080^{\circ} \mathrm{C}\right)$ when the rotational speed increased from $500 \mathrm{rpm}$ to $1000 \mathrm{rpm}$ (it indicates that no melting has taken place during the process and that the FSP is a solid state, low energy consumption route to produce surface level composites), (ii) the peak temperature, the rate of heating and cooling that are crucial to control grain growth, and (iii) the duration of the material exposed to a temperature higher than recrystallization temperature, which is also significant because it affects the grain growth during the process. It was observed that the heat generation and the peak temperature strongly depend on the tool rotational speed and also the rate of heating strongly depends on processing speed. Higher processing speed will reduce the processing time and subsequently the workpiece will stay with less time at higher temperatures and vice versa. As a result, the peak temperature during FSP increases strongly as the rotational speed increases and it decreases when the processing speed increases.

3.3. XRD Analysis. Figure 5 depicts the XRD patterns of nanosized $\mathrm{SiC}$ particles and the fabricated nanocomposite samples at different process parameter combinations. 


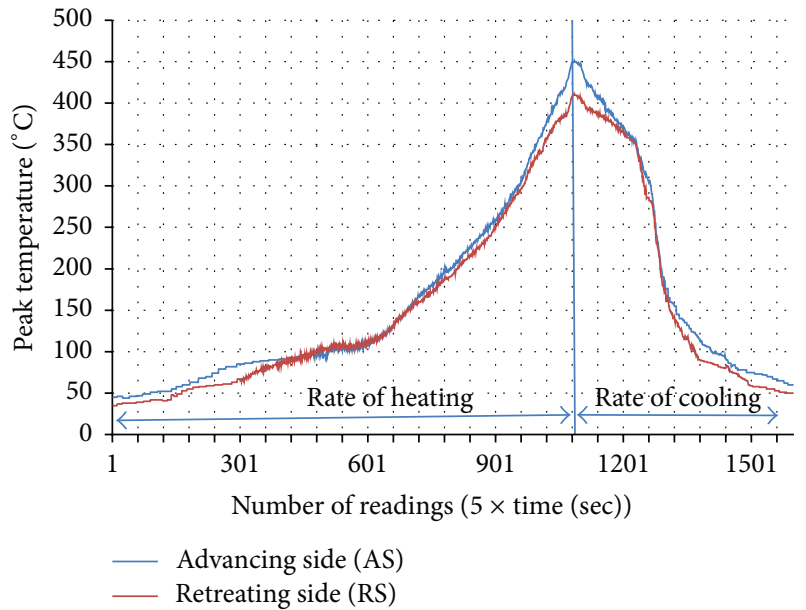

(a)

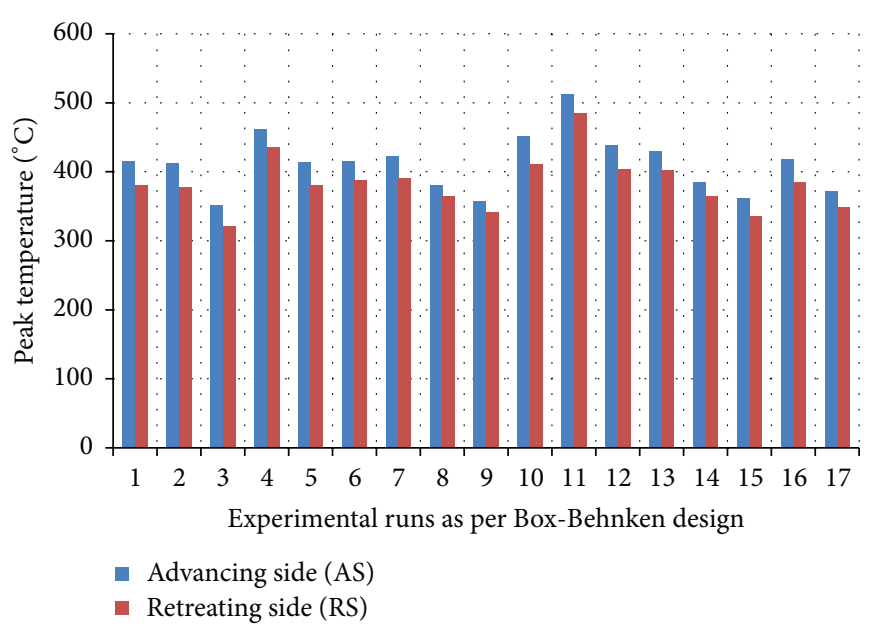

(b)

FIGURE 4: (a) Temperature distribution profile for sample at $750 \mathrm{rpm} / 20 \mathrm{~mm} / \mathrm{min} / 2^{\circ}$ and (b) peak temperature history during FSP runs in advancing and retreating side.

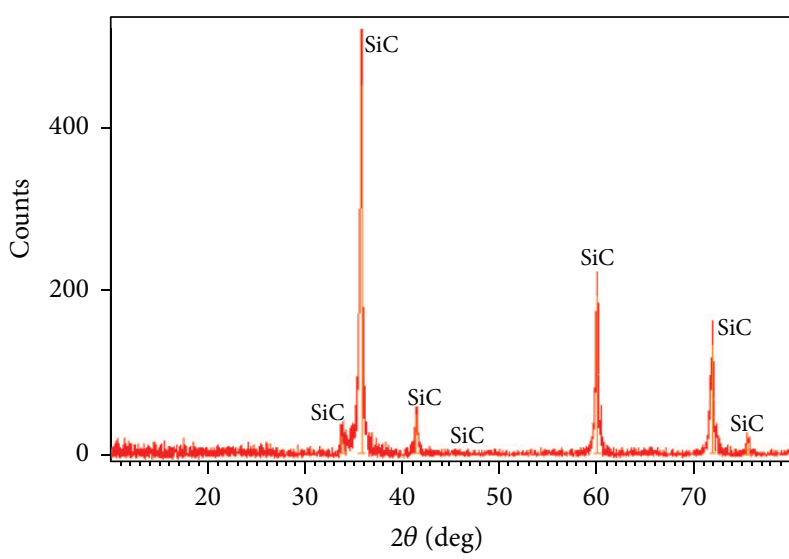

(a) Nanosized SiCp

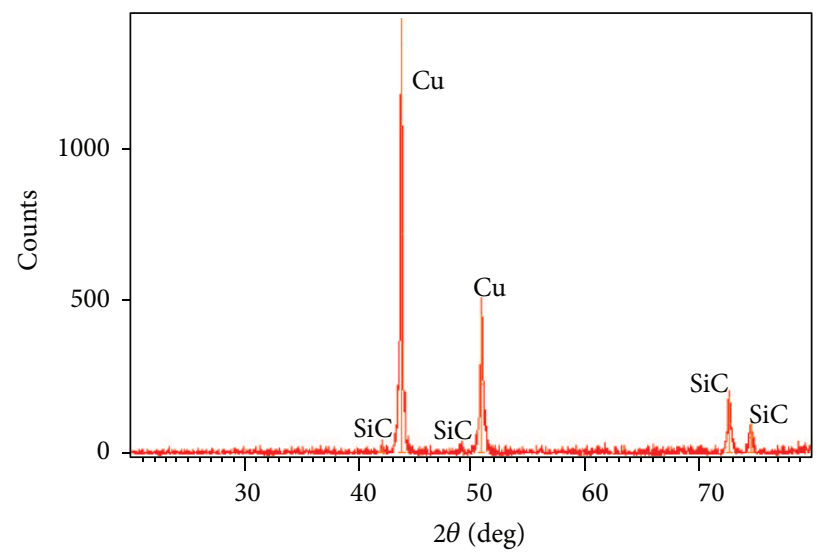

(c) $750 \mathrm{rpm} / 50 \mathrm{~mm} / \mathrm{min} / 2^{\circ}$

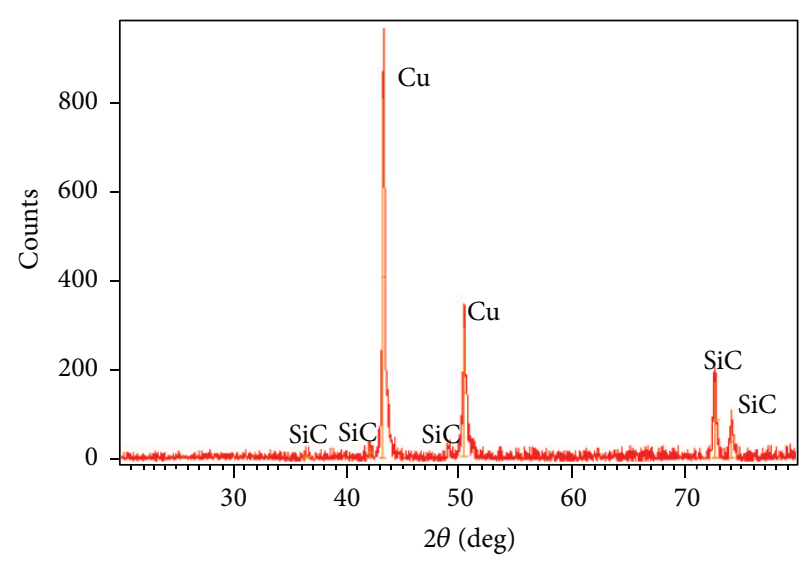

(b) $500 \mathrm{rpm} / 50 \mathrm{~mm} / \mathrm{min} / 1^{\circ}$

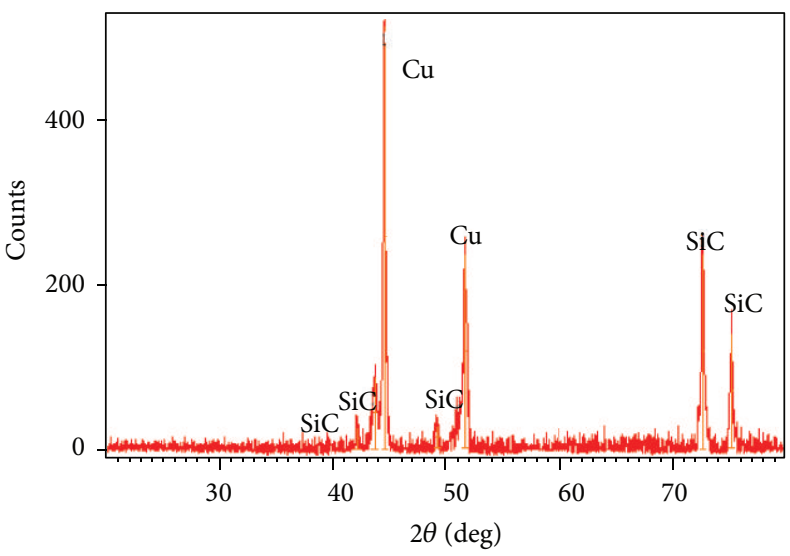

(d) $1000 \mathrm{rpm} / 50 \mathrm{~mm} / \mathrm{min} / 1^{\circ}$

FIGURE 5: X-ray diffraction pattern of (a) nanosized SiCp and (b-d) nanocomposites at process parameter combinations. 


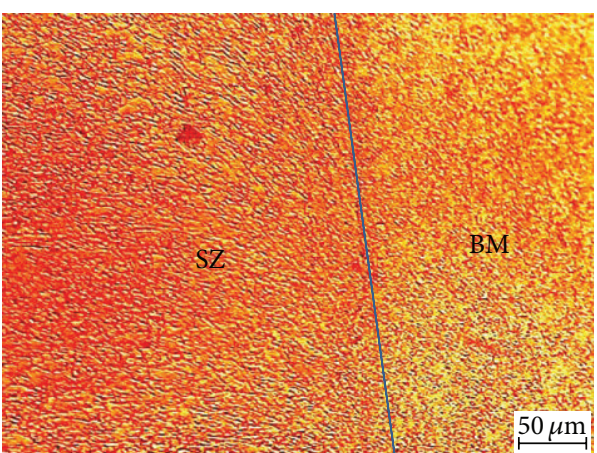

(a) $500 \mathrm{rpm} / 20 \mathrm{~mm} / \mathrm{min} / 1^{\circ}$

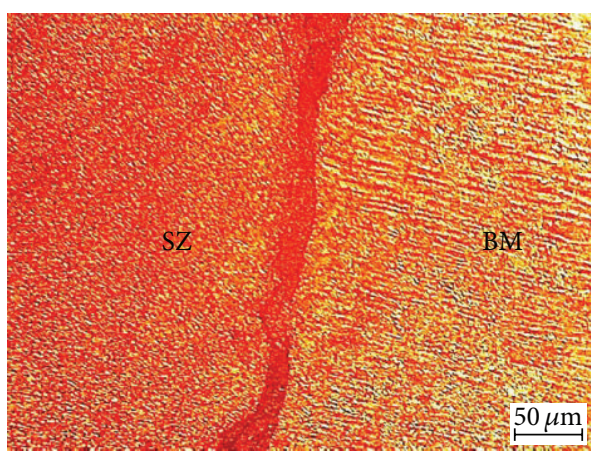

(c) $1000 \mathrm{rpm} / 20 \mathrm{~mm} / \mathrm{min} / 1^{\circ}$

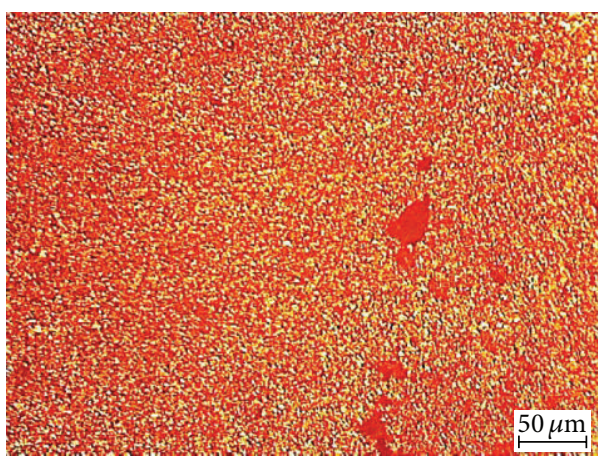

(e) $750 \mathrm{rpm} / 20 \mathrm{~mm} / \mathrm{min} / 2$

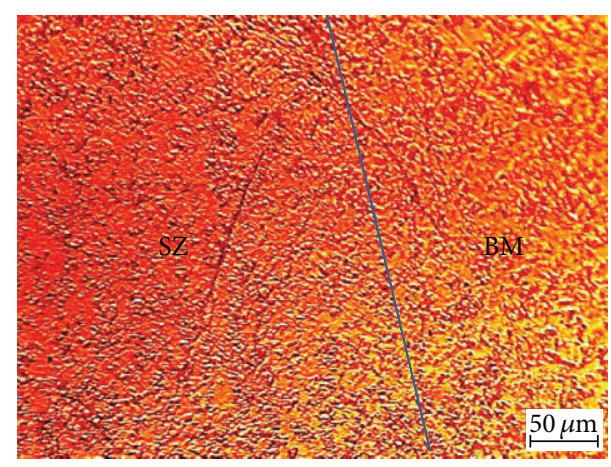

(b) $750 \mathrm{rpm} / 50 \mathrm{~mm} / \mathrm{min} / 0^{\circ}$

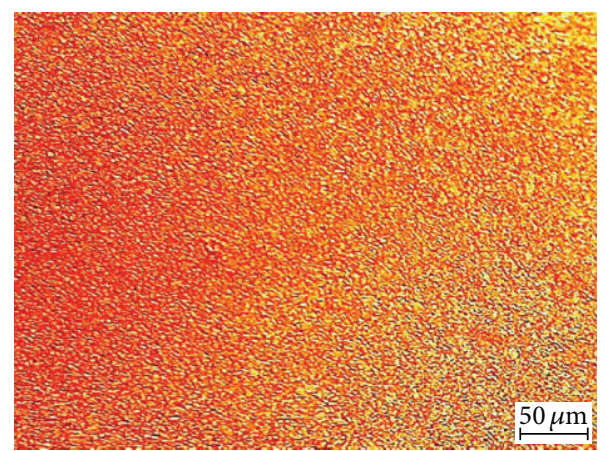

(d) $500 \mathrm{rpm} / 20 \mathrm{~mm} / \mathrm{min} / 1^{\circ}$

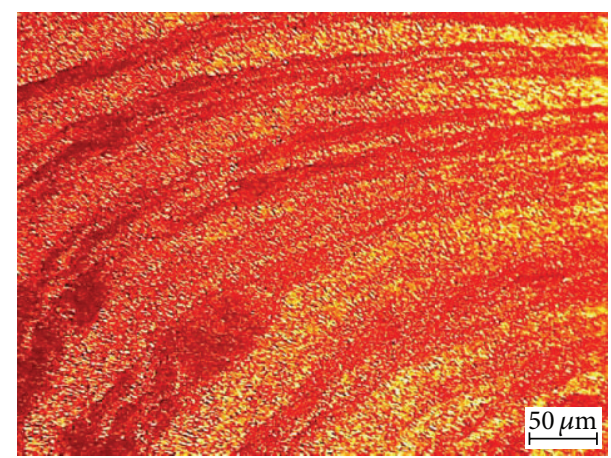

(f) $1000 \mathrm{rpm} / 20 \mathrm{~mm} / \mathrm{min} / 1^{\circ}$

FIGURE 6: Optical micrographs of nanocomposites at (a-c) the interface between SZ and BM and (d-f) SZ region at different parameter combinations.

The diffraction peaks of $\mathrm{SiCp}$ and its presence in the nanocomposites were seen in Figures 5(a) and 5(b)-5(d) at process parameter combinations. The peaks of $\mathrm{SiCp}$ in nanocomposites seem weak because the volume fraction of $\mathrm{SiCp}$ is smaller than that of copper [20]. It is also observed from Figures 5(b)-5(d) that there is no evidence of new phases (intermetallic compounds) which were attributed to an adequate heat generation during the FSP and also some $\mathrm{SiCp}$ reflections were disappeared, due to the good dispersion and particle size reduction of $\mathrm{SiC}$.

3.4. Microstructural Characterization. The FSP parameters influence growth of the grain and dynamic recrystallization during FSP directly decides the final structure of the composite [21]. Figure 6 shows the microstructural changes in nanocomposites by various process parameters combinations. Figures 6(a)-6(c) depict a smooth interface between SZ and $\mathrm{BM}$ was obtained during fabrication of nanocomposites at three different parameter combinations. It can be observed that the grain size of specimens with $\mathrm{SiCp}$ is much smaller (given in Table 2) at different process parameters (changes in heat-input), due to the nucleation of SiCp and restriction of grains growth due to the pinning effect of $\mathrm{SiC}$ particles [17], than the average grain size of the base metal ( $35 \mu \mathrm{m}$ as in Figure 1(a)).

Increase in heat-input (rotational speed from 500 to $1000 \mathrm{rpm}$ ) leads to grain growth as shown in Figures 6(d)6(f) due to dynamic recrystallization during FSP. A dispersion of second-phase particles helps to prevent the grain growth. Figure 6(f) shows that there is a characteristic onion 


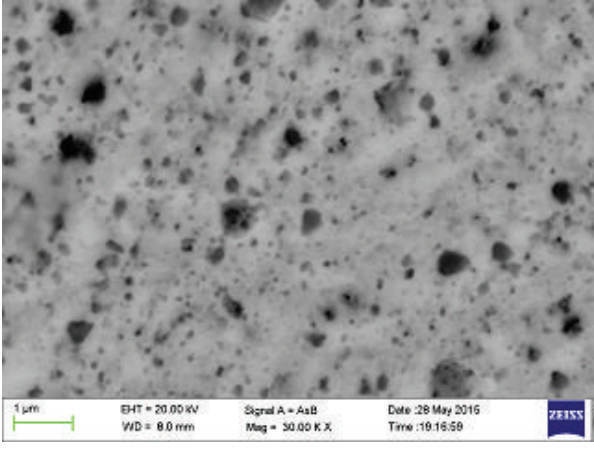

(a)

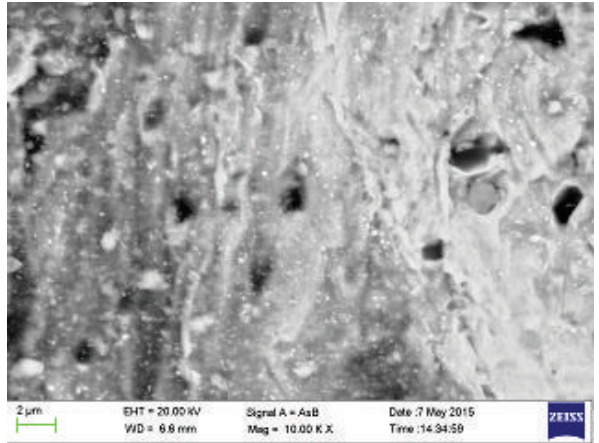

(b)

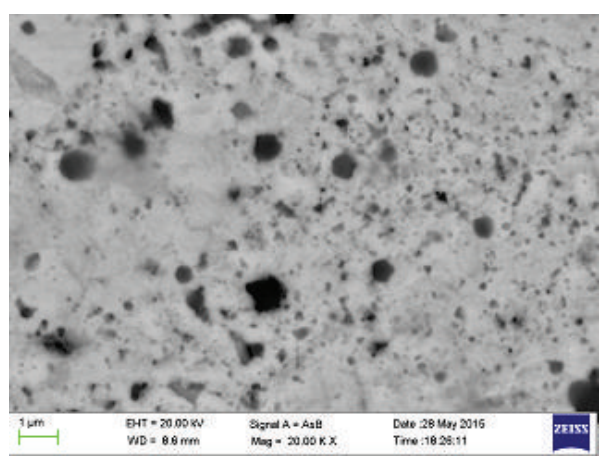

(c)

FIGURE 7: FESEM images of nanocomposites at different parameters: (a) $500 \mathrm{rpm} / 35 \mathrm{~mm} / \mathrm{min} / 2^{\circ}$, (b) $750 \mathrm{rpm} / 50 \mathrm{~mm} / \mathrm{min} / 2^{\circ}$, and (c) $1000 \mathrm{rpm} / 20 \mathrm{~mm} / \mathrm{min} / 1^{\circ}$.

ring at $1000 \mathrm{rpm} / 20 \mathrm{~mm} / \mathrm{min} / 1^{\circ}$ due to high heat generation during FSP where the nanosized $\mathrm{SiC}$ particles are predominantly spread in this regime by the vigorous stirring action during FSP at the working temperature around $513^{\circ} \mathrm{C}$. It was also observed that increasing of processing speed leads to a decrease in the duration of the time in which the material is affected by the process heat. The most important part of the tool is the pin, which plays a crucial role in material flow and mixing [22]. The straight cylindrical tool pin profile made uniform distribution of $\mathrm{SiC}$ particles in $\mathrm{Cu}$ based metal matrix composites [23].

FESEM images as in Figure 7 show that surface nanocomposite layers were successfully obtained and had good distribution of nanoparticles and good bonding with matrix under different process parameter combinations. Therefore, FSP was used successfully as low energy consumption route for the fabrication of surface level nanocomposites. It was observed that the copper based surface level nanocomposites produced by FSP route using straight cylindrical threaded pin profile enhance the $\mathrm{SiC}$ particle distribution in the copper matrix. This observation was well supported by Azizieh et al. [24] findings in $\mathrm{AZ31} / \mathrm{Al}_{2} \mathrm{O}_{3}$ nanocomposites fabricated by FSP using a threaded pin profile. Also, FSP can be successfully used for fabrication of nanocomposite layers with uniform distribution of SiCp at low heat-input as shown in Figure 7(a) under the condition $2^{\circ}$ tool tilt angle (providing good forging/compaction and stirring action) and rotational and processing speed of $500 \mathrm{rpm}$ and $35 \mathrm{~mm} / \mathrm{min}$, respectively.
Figures $7(\mathrm{~b})$ and $7(\mathrm{c})$ show the good distribution of $\mathrm{SiC}$ particles in copper matrix at two different process parameter combinations with rotational speed of $750 \mathrm{rpm}$ and $1000 \mathrm{rpm}$, respectively. Results by EDAX composition analysis as in Figure 8 (a) show the presence of elements like $\mathrm{Si}, \mathrm{C}$, and $\mathrm{Cu}$ in a sample processed at $500 \mathrm{rpm} / 35 \mathrm{~mm} / \mathrm{min} / 2^{\circ}$. The mapping image of a sample processed at $1000 \mathrm{rpm} / 20 \mathrm{~mm} / \mathrm{min} / 1^{\circ}$ in Figure 8(b) shows clearly the presence of $\mathrm{Si}, \mathrm{C}$, and $\mathrm{Cu}$. After FSP, the percentage of SiCp in the surface nanocomposite was found to be $1.75 \%$ by volume.

3.5. Microhardness. The microhardness of samples was measured by Vickers microhardness tester. The base metal showed an average hardness of $97 \mathrm{HV}$. The average microhardness values at the cross section of stir zone of the surface nanocomposites are shown in Figure 9 and listed in Table 2. It was observed that the average microhardness of a surface nanocomposite by FSP was about 95\% higher than that of pure copper matrix. The grain refinement in the nanocomposites produced by FSP is related to the presence of the $\mathrm{SiC}$ particles which were uniformly distributed among the grain boundaries of the matrix and restricted the grain growth during the solidification. In all the fabricated nanocomposites, the increase in hardness in stir zone region of nanocomposites was due to (i) hard phase dispersion of nanosized SiCp (Orowan strengthening mechanism), (ii) grain refinement in stir zone (Hall-Petch relationship), (iii) quench hardening effect due to the variation in thermal 

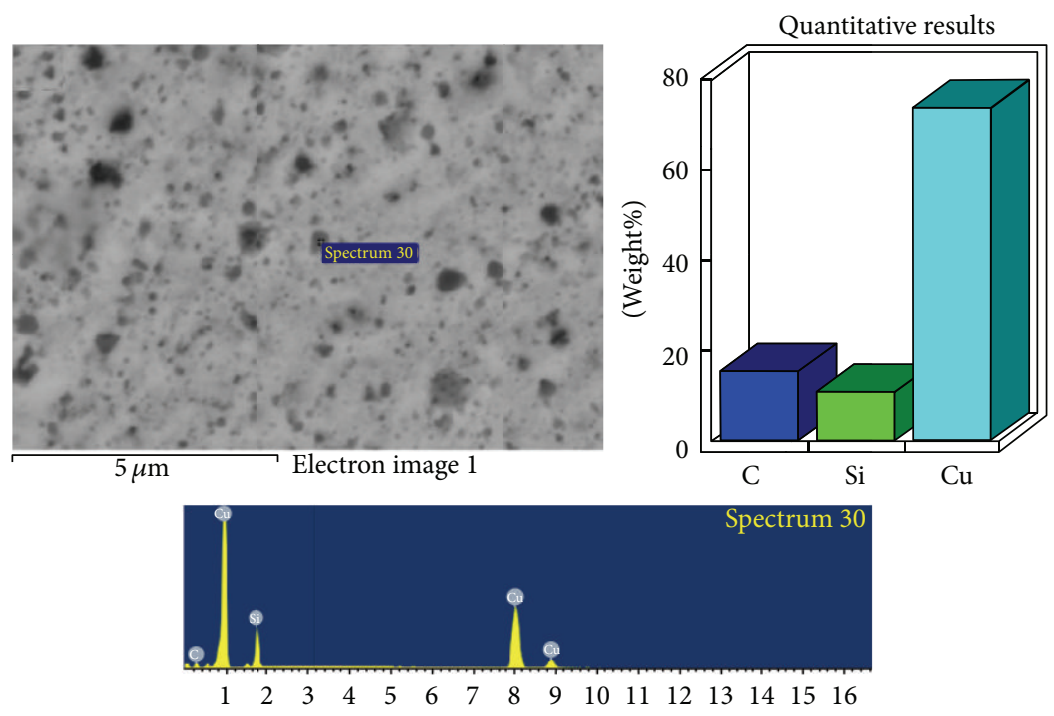

$(\mathrm{keV})$

Full scale 39376 cts cursor: 3.142 (740 cts)

(a)

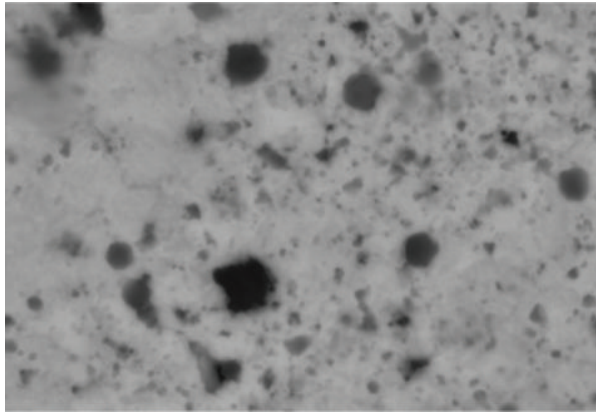

Electron image 1

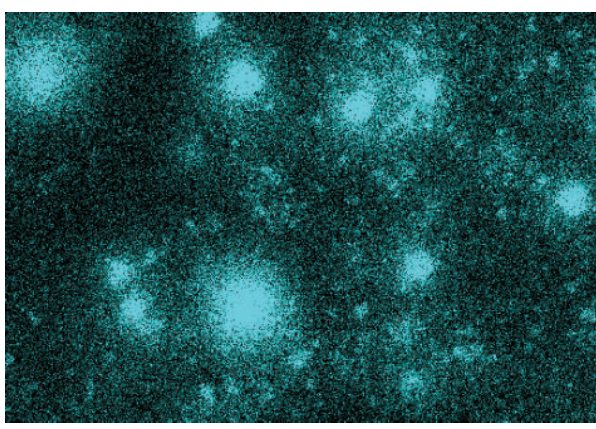

Si Ka1

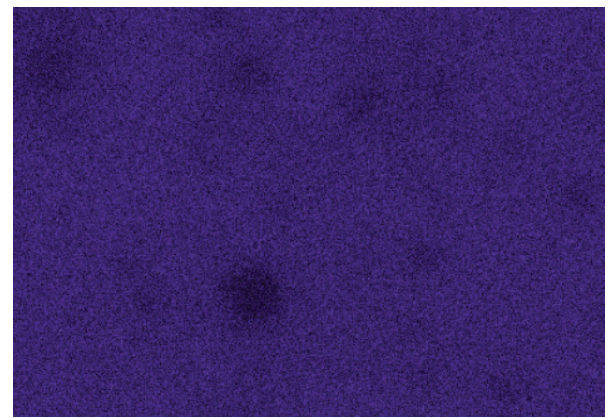

$\mathrm{Cu} \mathrm{Ka} 1$

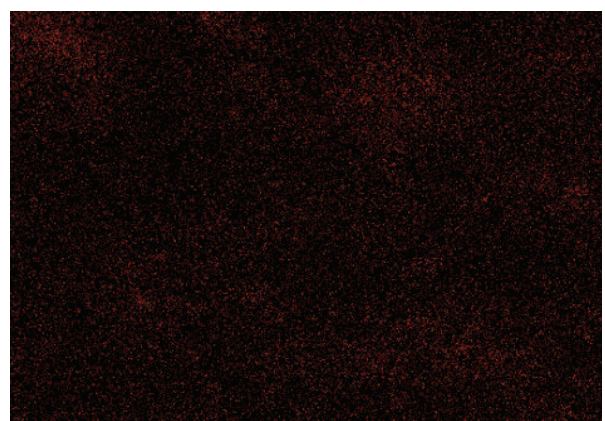

C Kal_2

(b)

Figure 8: (a) EDAX report of a sample processed at (a) $500 \mathrm{rpm} / 35 \mathrm{~mm} / \mathrm{min} / 2^{\circ}$ and (b) mapping image of a sample processed at $1000 \mathrm{rpm} / 20 \mathrm{~mm} / \mathrm{min} / 1^{\circ}$.

reduction between SiCp and pure copper, and (iv) work hardening effect caused by the strain misfit between the elastic $\mathrm{SiCp}$ and the plastic pure copper.

It can be observed that the increase in tool rotational speed from 500 to $1000 \mathrm{rpm}$ results in increase in grain size which decreases the hardness (as in Figure 9 and Table 2) of the surface nanocomposites. Similarly, increase in processing speed from 20 to $50 \mathrm{~mm} / \mathrm{min}$ enhances the microhardness due to the pinning effect of SiCp. Also, the increase in tool tilt angle from $0^{\circ}$ to $2^{\circ}$ leads to a considerable changes in hardness enhancement due to its good forging/compaction and effective distribution of SiCp by stirring action during FSP. The best condition for preparing $\mathrm{Cu} / \mathrm{SiCp}$ nanocomposite by FSP with the goal of maximizing the hardness was found to be $500 \mathrm{rpm}, 50 \mathrm{~mm} / \mathrm{min}$, and $1^{\circ}$ based on desirability analysis. 


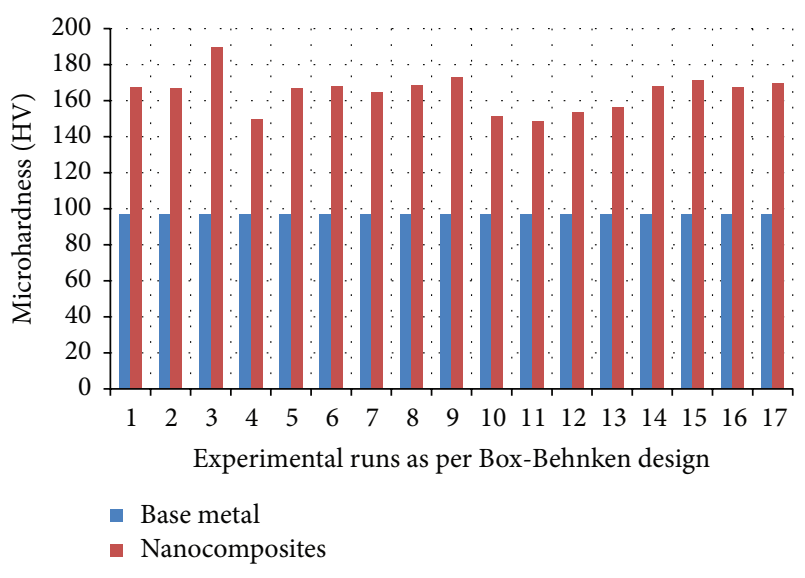

FIGURE 9: Microhardness of base metal and fabricated nanocomposites.

\section{Conclusions}

From these investigations, the following conclusions can be derived:

(i) FSP is a successful low energy consumption route for preparing surface level nanocomposites.

(ii) A set of blind holes $(2 \mathrm{~mm}$ in diameter and $3 \mathrm{~mm}$ in depth) was used as a successful particulate deposition technique to prepare surface level nanocomposites by FSP route with uniform distribution of nanosized $\mathrm{SiCp}$ in the copper matrix.

(iii) Box-Behnken design (three factors with three levels) was used in FSP experimentation and observed that the heat generation (heat-input) and peak temperature during FSP play a vital role in controlling the microstructural changes and microhardness of processed nanocomposites.

(iv) By changing the process parameters, the grain size in the $\mathrm{SZ}$ region of nanocomposites can be altered based on heat-input and its rate of heating/cooling during FSP.

(v) The peak temperature experienced in the advancing side during FSP increased with increase of rotational speed but decreased by increasing of processing speed. The tool tilt angle has less effect on peak temperature than rotational and processing speed during FSP.

(vi) The enhancements of hardness in nanocomposites were achieved by decreasing the rotational speed and increasing processing speed. The hardness can also be considerably enhanced by increasing the tool tilt angle due to its good forging/compaction during FSP.

(vii) The best condition for surface level nanocomposite by FSP was $500 \mathrm{rpm} / 50 \mathrm{~mm} / \mathrm{min} / 1^{\circ}$ based on desirability analysis where the hardness was about $95 \%$ higher than as-received $\mathrm{Cu}$.

\section{Conflict of Interests}

The authors declare that there is no conflict of interests regarding the publication of this paper.

\section{References}

[1] J. T. Jiang, L. Zhen, C. Y. Xu, and X. L. Wu, "Microstructure and magnetic properties of SiC/Co composite particles prepared by electroless plating," Surface and Coatings Technology, vol. 201, no. 6, pp. 3139-3146, 2006.

[2] A. N. Attia, "Surface metal matrix composites," Materials and Design, vol. 22, no. 6, pp. 451-457, 2001.

[3] S. Romankov, Y. Hayasaka, I. V. Shchetinin, J.-M. Yoon, and S. V. Komarov, "Fabrication of $\mathrm{Cu}-\mathrm{SiC}$ surface composite under ball collisions," Applied Surface Science, vol. 257, no. 11, pp. 50325036, 2011.

[4] R. S. Mishra and Z. Y. Ma, "Friction stir welding and processing," Materials Science and Engineering R: Reports, vol. 50, no. 1-2, pp. 1-78, 2005.

[5] R. S. Mishra and M. W. Mahoney, Friction Stir Welding and Processing, ASM International Materials, 2007.

[6] R. S. Mishra, Z. Y. Ma, and I. Charit, "Friction stir processing: a novel technique for fabrication of surface composite," Materials Science and Engineering A, vol. 341, no. 1-2, pp. 307-310, 2003.

[7] Z. Y. Ma, "Friction stir processing technology: a review," Metallurgical and Materials Transactions A, vol. 39, no. 3, pp. 642-658, 2008.

[8] Y. X. Gan, D. Solomon, and M. Reinbolt, "Friction stir processing of particle reinforced composite materials," Materials, vol. 3, no. 1, pp. 329-350, 2010.

[9] H. S. Arora, H. Singh, and B. K. Dhindaw, "Composite fabrication using friction stir processing-a review," International Journal of Advanced Manufacturing Technology, vol. 61, no. 912, pp. 1043-1055, 2012.

[10] S. Cartigueyen and K. Mahadevan, "Role of friction stir processing on copper and copper based particle reinforced composites-a review," Journal of Materials Science \& Surface Engineering, vol. 2, no. 2, pp. 133-145, 2015.

[11] P. Asadi, M. K. B. Givi, K. Abrinia, M. Taherishargh, and R. Salekrostam, "Effects of SiC particle size and process parameters on the microstructure and hardness of AZ91/SiC composite layer fabricated by FSP," Journal of Materials Engineering and Performance, vol. 20, no. 9, pp. 1554-1562, 2011.

[12] M. Barmouz, P. Asadi, M. K. B. Givi, and M. Taherishargh, "Investigation of mechanical properties of $\mathrm{Cu} / \mathrm{SiC}$ composite fabricated by FSP: effect of SiC particles' size and volume fraction," Materials Science and Engineering A, vol. 528, no. 3, pp. 1740-1749, 2011.

[13] J. M. Valverde, A. Castellanos, A. Ramos, and P. K. Watson, "Avalanches in fine, cohesive powders," Physical Review E, vol. 62, no. 5, pp. 6851-6860, 2000.

[14] H. R. Akramifard, M. Shamanian, M. Sabbaghian, and M. Esmailzadeh, "Microstructure and mechanical properties of $\mathrm{Cu} / \mathrm{SiC}$ metal matrix composite fabricated via friction stir processing," Materials \& Design, vol. 54, pp. 838-844, 2014.

[15] M. Sabbaghian, M. Shamanian, H. R. Akramifard, and M. Esmailzadeh, "Effect of friction stir processing on the microstructure and mechanical properties of $\mathrm{Cu}-\mathrm{TiC}$ composite," Ceramics International, vol. 40, no. 8, pp. 12969-12976, 2014. 
[16] R. Sathiskumar, N. Murugan, I. Dinaharan, and S. J. Vijay, "Role of friction stir processing parameters on microstructure and microhardness of boron carbide particulate reinforced copper surface composites," Indian Academy of Sciences, vol. 38, part 6, pp. 1433-1450, 2013.

[17] M. Barmouz, M. K. B. Givi, and P. Asadi, "Production of Cu/SiC nanocomposite layers by friction stir processing," Defect and Diffusion Forum, vol. 312-315, pp. 319-324, 2011.

[18] S. Cartigueyen, O. P. Sukesh, and K. Mahadevan, "Numerical and experimental investigations of heat generation during friction stir processing of copper," Procedia Engineering, vol. 97, pp. 1069-1078, 2014.

[19] Y. M. Hwang, P. L. Fan, and C. H. Lin, "Experimental study on Friction Stir Welding of copper metals," Journal of Materials Processing Technology, vol. 210, no. 12, pp. 1667-1672, 2010.

[20] D. Schwarzenbach, Crystallography, Translated from French by A. Alan Pinkerton, Institute of Crystallography, University of Lausanne, Lausanne, Switzerland; University of Toledo, Toledo, Ohio, USA, 1996.

[21] C. I. Chang, X. H. Du, and J. C. Huang, "Achieving ultrafine grain size in $\mathrm{Mg}-\mathrm{Al}-\mathrm{Zn}$ alloy by friction stir processing," Scripta Materialia, vol. 57, no. 3, pp. 209-212, 2007.

[22] M. Salehi, M. Saadatmand, and J. Aghazadeh Mohandesi, "Optimization of process parameters for producing AA6061/SiC nanocomposites by friction stir processing," Transactions of Nonferrous Metals Society of China, vol. 22, no. 5, pp. 1055-1063, 2012.

[23] M. Barmouz, M. K. B. Givi, and J. Jafari, "Influence of tool pin profile on the microstructure and mechanical behavior of $\mathrm{Cu} / \mathrm{SiC}$ metal matrix composites produced by friction stir processing," Advanced Materials Research, vol. 154-155, pp. 17611766, 2011.

[24] M. Azizieh, A. H. Kokabi, and P. Abachi, "Effect of rotational speed and probe profile on microstructure and hardness of $\mathrm{AZ31} / \mathrm{Al}_{2} \mathrm{O}_{3}$ nanocomposites fabricated by friction stir processing," Materials and Design, vol. 32, no. 4, pp. 2034-2041, 2011. 

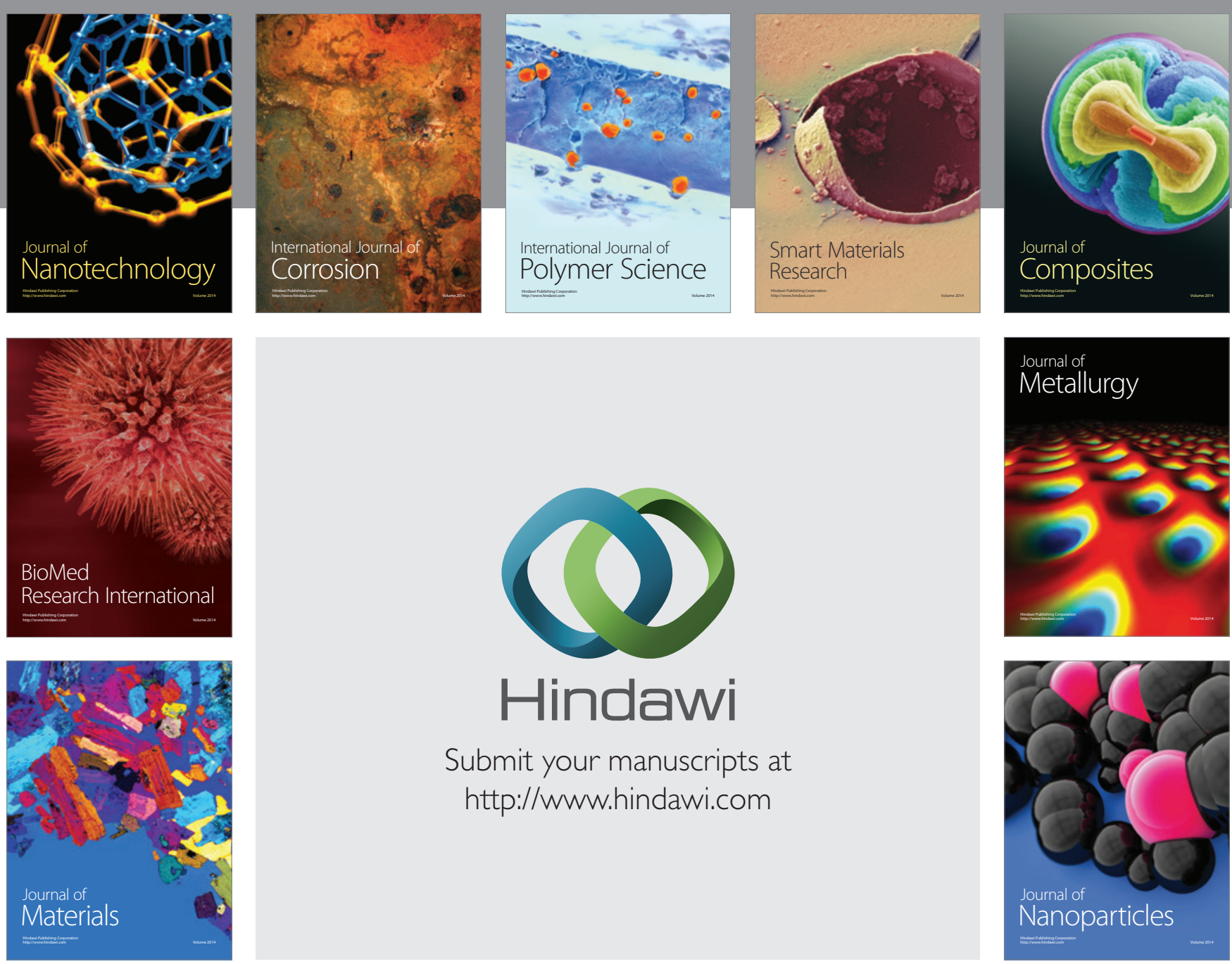

Submit your manuscripts at http://www.hindawi.com
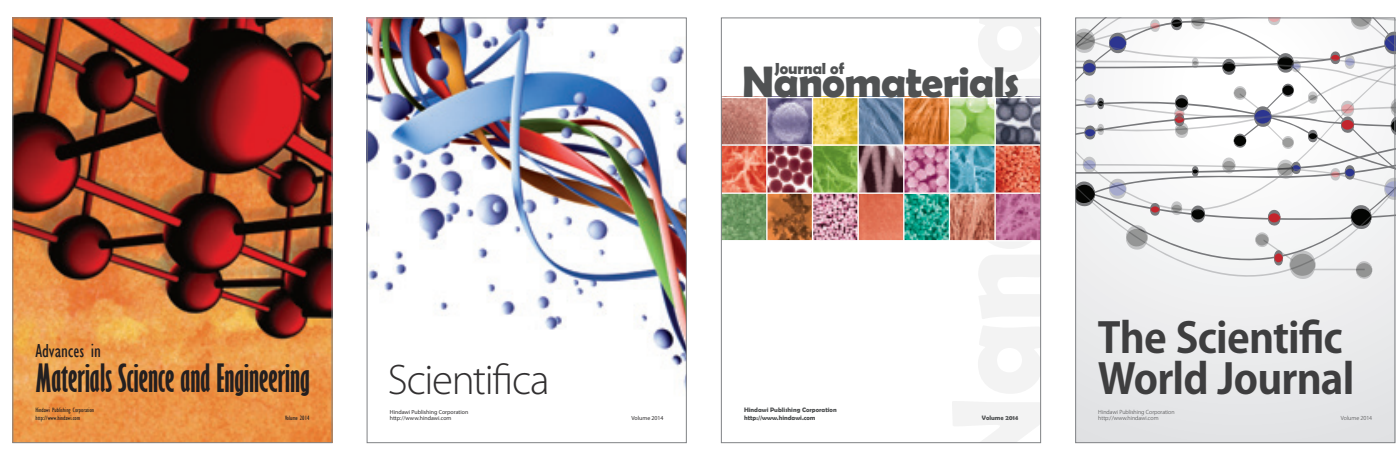

\section{The Scientific World Journal}
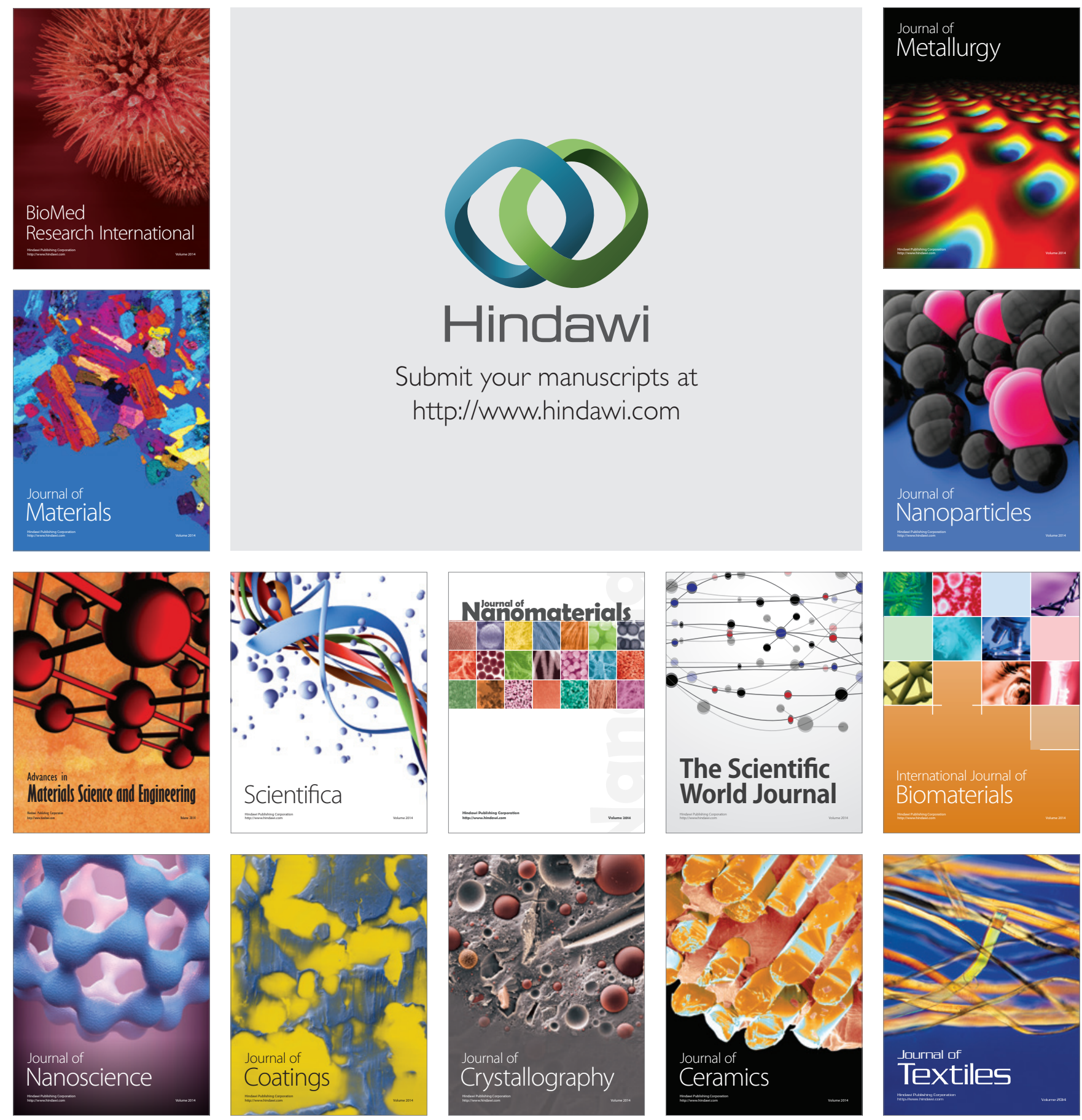